Research Article

\title{
Transient Pulse Test for Non-Darcy Flow Behaviors and Hydromechanical Coupling Effect of Fractured Limestone
}

\author{
JianChao Cheng, YanLin Zhao $(D)$, Yang Li, Tao Tan, and Le Chang \\ Hunan Provincial Key Laboratory of Safe Mining Techniques of Coal Mines, \\ Work Safety Key Lab on Prevention and Control of Gas and Roof Disasters for Southern Coal Mines, \\ Hunan University of Science and Technology, Xiangtan, Hunan 411201, China \\ Correspondence should be addressed to YanLin Zhao; yanlin_8@163.com
}

Received 3 June 2020; Revised 16 July 2020; Accepted 26 July 2020; Published 13 August 2020

Academic Editor: Chunshun Zhang

Copyright (c) 2020 JianChao Cheng et al. This is an open access article distributed under the Creative Commons Attribution License, which permits unrestricted use, distribution, and reproduction in any medium, provided the original work is properly cited.

\begin{abstract}
In this paper, the transient pulse test is used to study the permeability and hydromechanical coupling effect of the fractured limestone. The permeability parameters (permeability, $\beta$ factor of non-Darcy flow, and acceleration coefficient) of non-Darcy flow in fractured limestone are obtained by experimental data. The experimental results show that, in the process of transient seepage test of fractured Maokou limestone, the relationship between hydraulic pressure gradient and seepage velocity does not conform to Darcy's law but meets Forchimer relationship. The relationship between hydraulic pressure difference and time can be fitted by quartic polynomial. The larger the confining pressure is, the more obvious the non-Darcy seepage effect of fractured rock seepage is. The seepage of rock fracture under high confining pressure is a highly nonlinear time-varying seepage. The permeability coefficient of rock decreases with the increase of volume stress. Under the action of low volume stress, the relationship between permeability coefficient and stress is more sensitive, while under the action of high volume stress, the relationship between permeability coefficient and volume stress is not significant. In the process of volume stress increasing, the $\beta$ factor of non-Darcy flow appears negative. Under the action of low volume stress, the acceleration coefficient and $\beta$ factor of non-Darcy flow increase, while under the action of high volume stress, the acceleration coefficient and $\beta$ factor of non-Darcy flow decrease.
\end{abstract}

\section{Introduction}

Fractured rock mass, which is potentially dangerous, is widely existing in nature. The seepage instability of fractured rock mass is an important reason for rock engineering destruction and even large-scale geological disasters. Therefore, the hydraulic coupling and seepage characteristics of fractured rock masses are generally concerned [1-6]. Consequently, experts and scholars have proposed a variety of mathematical models of seepage. For example, Dverstorp and Andersson [7] use a discrete fracture network model to conduct seepage analysis of fractured rock mass, and Zhao [8] has proposed a dualmedium multifield coupling model. And many experiments of fluid-solid coupling have been done [9-15].

The rock permeability is usually studied by the steadystate method or the transient method. Miao et al. used steady-state method to test the seepage performance of broken sandstone under different porosity conditions [16-19]. Wang et al. measured the rock seepage rate by transient method and analyzed the hydrodynamic characteristics of transient method in rock permeability test by using the hydrodynamic theory in porous media [20,21]. Hsieh et al. found that the transient method is suitable for low permeable rocks and tested the permeability of a variety of different geological materials with the transient method [22-27].

It is found that, under the condition of low water pressure, the coarse fractured rock mass has Darcy flow characteristics, and under the condition of high hydraulic pressure, the seepage of rock mass has Darcy flow characteristics, and the hydraulic pressure plays an important role in the development of rock fracture [28-32]. Li et al. [33] 
discovered the variation of rock permeability with rock porosity by studying rocks with different particle sizes. Zhao et al. [34] found that the seepage curve of low permeability rock has obvious non-Darcy seepage characteristics through transient pulse method and used a new data analysis method to study the relationship between velocity and hydraulic gradient. Nguyen et al. [35] studied the effect of stress path on the mechanical properties and coupled permeability evolution of quartz sand filling and soft sandstone. The seepage of the fractured rock mass is controlled by the shape of the fracture, so many models and parameters have been proposed to characterize the fracture [36-43]. In addition, factors affecting rock permeability include rock type, loading method, and damage history [44-50].

It can be seen from overview of the references that although there are many researches on the seepage of fractured rock mass, these researches mainly focus on the use of steady-state and transient methods to study the factors affecting the seepage of rock, the extraction of non-Darcy flow permeability coefficient mainly focuses on permeability, and the research on the extraction of acceleration coefficient and non-Darcy flow $\beta$ factor is less. In this paper, the transient pulse test is carried out on the fractured limestone produced by splitting method. The test data of the hydraulic pressure varying with time of fractured limestone under the action of constant axial pressure and variable confining pressure is obtained by MTS815 [34, 51], the permeability coefficient of non-Darcy flow is extracted, and its permeability characteristics and hydromechanical coupling effect are studied, and the seepage law of fractured Maokou limestone under different confining pressures is revealed. According to the data about permeability coefficient, volume stress, and hydraulic pressure difference, the law of change among them can be obtained. It has a certain guiding effect on the seepage problem of fractured rock mass in practical engineering.

\section{Test Method}

2.1. Specimen Preparation. In this paper, Maokou limestone from Ningxiang coal mine of Hunan Province was used to make a sample of $\Phi 50 \times 100 \mathrm{~mm}$. The limestone in Maokou is very dense, so it is necessary to induce some fractures artificially for seepage experiment. The artificial fractures were obtained by Brazil splitting method. Firstly, the standard rock sample of $\Phi 50 \times 100 \mathrm{~mm}$ with no damage on the edge and smooth end face was selected. Then a layer of glue on the outer surface of the rock sample was evenly applied, and a layer of thermoplastic tube with the same height as the rock sample was covered. Next the heat gun was used to close the thermoplastic tube from top to bottom. Finally, the Brazilian splitting method was used to conduct the splitting test on the rock sample. In order to prevent the instant brittle failure of the test sample, which leads to the failure of rock sample production, the loading rate of the test is strictly controlled to $10 \mathrm{~N} / \mathrm{s}$ until the rock fracture occurs; the test is stopped immediately.

Figure 1 is the induced fracture diagram of Brazil splitting method, and Figure 2 is the fracture end face photo and fracture path sketch of the test piece.
The sample fracture was marked with a pen at different parts, especially at the places where the gap width is obviously different, so that the measured value can represent the gap width of the fracture more accurately. The fracture of the end face of the rock sample at the serial number was measured with a fracture microscope, each reading was recorded, and the average value of all the measured values is the gap width of the fracture. Table 1 is the measurement value of initial crack width of rock sample terminal face.

2.2. Seepage Experiments. The test is carried out on MTS815 rock mechanics multifunctional testing machine, which is produced by MTS company of the United States and is specially used for testing rock and concrete and other materials. It has four independent control systems, which are axial force, confining pressure, hydraulic pressure, and temperature, and it is at international leading level in testing rock and concrete materials. It is mainly used for various dynamic tests and static tests of rock and concrete materials, including uniaxial compression test, uniaxial tensile test, fracture strength, triaxial pressure, osmotic pressure, hydraulic pressure, temperature simulation, and other rock-related physical property analysis applications, which provides the test means for the research and analysis of dynamic characteristics of these materials and structures. It is the most advanced indoor rock mechanics test equipment (Figure 3). The main technical parameters of MTS815 are as follows: the axial force system: the overall rigidity of testing machine frame is $10.5 \times 109 \mathrm{~N} / \mathrm{m}$, maximum axial force can be loaded to $4600 \mathrm{kN}$, and maximum axial tension can be loaded to $2300 \mathrm{kN}$; the confining pressure system: the maximum confining pressure can be loaded to $140 \mathrm{MP}$; the hydraulic pressure system: the maximum hydraulic pressure can be loaded to $140 \mathrm{MPa}$, and the pressure difference and seepage flow can be measured; the temperature system: it can provide a temperature between $20^{\circ} \mathrm{C}$ and $200^{\circ} \mathrm{C}$.

The seepage test of rock fracture under cyclic loading and unloading was carried out in the triaxial pressure chamber of MTS815. During the test, when the stress reaches the preset value, the hydraulic pressure loading system is used to apply the same pressure on both ends of the rock sample and then reduce the hydraulic pressure at one end. At this way, the hydraulic pressure difference between the two ends of the rock sample is formed, collecting the series of the hydraulic pressure difference of the fracture varying with time and calculating the permeability characteristics. Table 2 shows the stress and hydraulic pressure used in the test. Figure 4 is the flowchart of seepage test of rock fracture under cyclic loading and unloading.

\section{Permeability Parameter Calculation}

There are two methods to determine the permeability of rock samples: steady-state method and transient method. The transient method is to record the change value of the hydraulic pressure gradient with time in the process of rock seepage and calculate the change rate of the hydraulic pressure gradient. The permeability characteristics of rock 


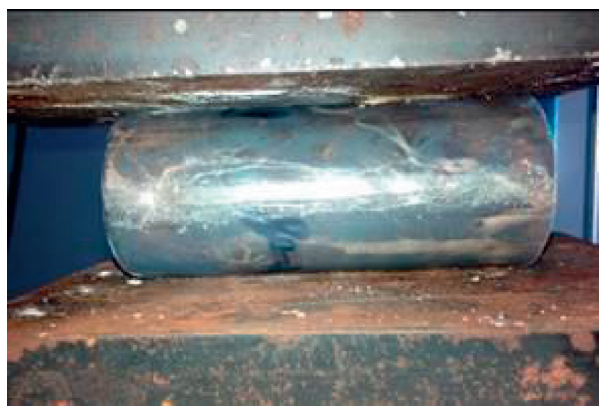

Figure 1: The induced fracture diagram of the Brazil splitting method.
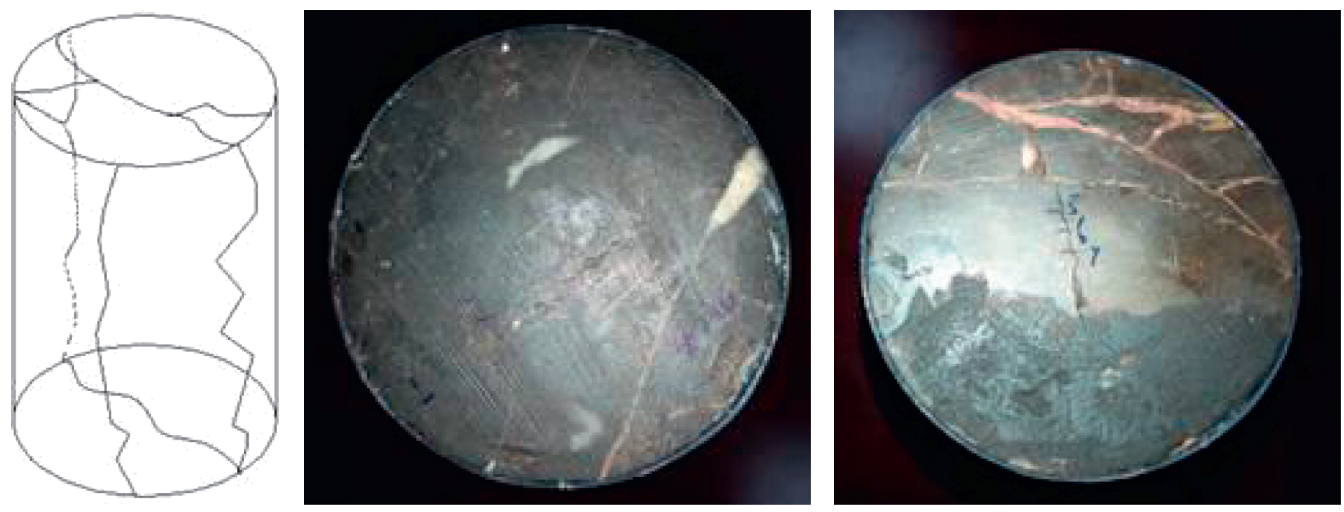

Figure 2: Fracture end face photo and fracture path sketch of the test piece.

TABLE 1: Initial crack width of the rock sample terminal face.

\begin{tabular}{lccccccccc}
\hline Specimen number $(\mathrm{mm})$ & 1 & 2 & 3 & 4 & 5 & 6 & 7 & Average value \\
\hline M07 & 0.28 & 0.18 & 0.17 & 0.26 & 0.18 & 0.22 & 0.48 & 0.25 \\
\hline
\end{tabular}

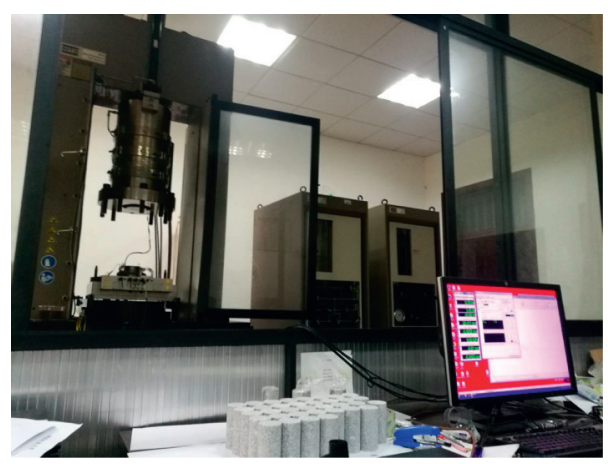

Figure 3: The MTS815 testing system.

TABLE 2: Test stresses and hydraulic pressure environment.

\begin{tabular}{lcccc}
\hline $\begin{array}{l}\text { Axial pressure/ } \\
\mathrm{MPa}\end{array}$ & $\begin{array}{c}\text { Confining } \\
\text { pressure/MPa }\end{array}$ & $\begin{array}{c}\text { Hydraulic pressure at the upper } \\
\text { end of the specimen } P 1 / \mathrm{MPa}\end{array}$ & $\begin{array}{c}\text { Hydraulic pressure at the } \\
\text { bottom of the specimen } P 2 / \mathrm{MPa}\end{array}$ & $\begin{array}{c}\text { Initial hydraulic pressure } \\
\text { difference } \Delta \mathrm{P}=P 1-P 2 / \mathrm{MPa}\end{array}$ \\
\hline & 4 & & & \\
6 & 6 & 3.0 & & \\
6 & 8 & & & \\
10 & & & \\
12 & & & \\
& & & & \\
\end{tabular}




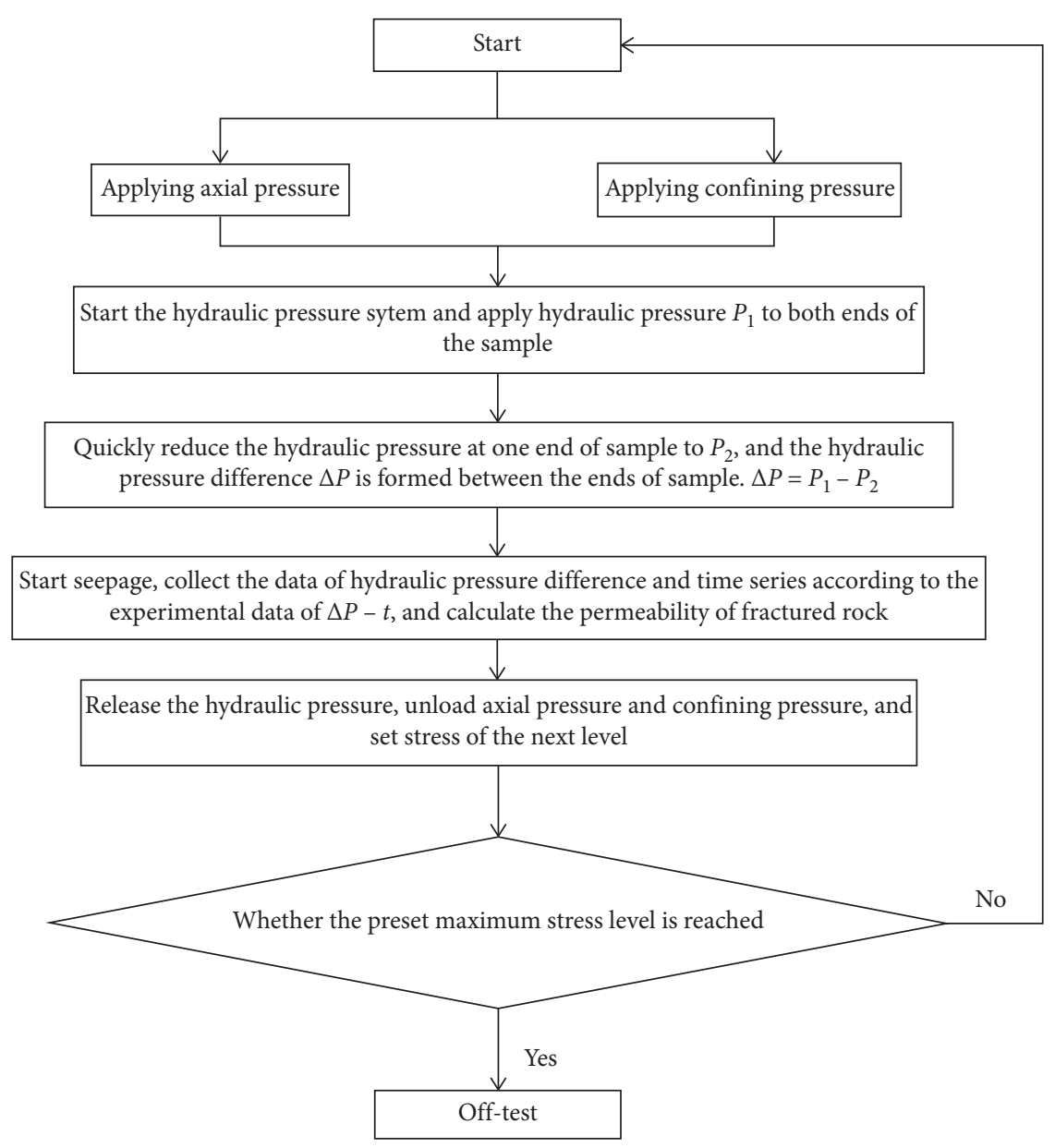

FIGURE 4: Flowchart of seepage test of fractured rock under cyclic loading and unloading.

can be obtained through the fitting curve of the hydraulic pressure gradient and its rate of change.

Figure 5 shows the test principle of permeability characteristics. The volume of both chambers in MTS hydraulic pressure system is $\mathrm{B}$, and their hydraulic pressures are $P 1$ and $P 2$, respectively. The cross-sectional area and height of rock sample are $A$ and $H$, respectively. Since the hydraulic pressure at both ends of rock sample is different at the initial time $\left(p_{10}>p_{20}\right)$, there will be a hydraulic pressure gradient $\xi_{0}=\left(p_{20}-p_{10}\right) / H$. The liquid in chamber 1 will enter into chamber 2 through the rock sample, which will cause the hydraulic pressure in chamber 1 to decrease continuously, while the hydraulic pressure in chamber 2 will rise continuously until the hydraulic pressure in the two chambers is equal, so as to reach the equilibrium state. Suppose that the mass flow of the water penetrating the rock sample from chamber 1 is $q$, and the rock sample is saturated with water. Then the mass flow of water from the rock sample into the chamber 2 is $q$ as well, and the seepage velocity of water in the rock sample is $V=q / \rho A$. From the compressibility of the fluid, we can obtain

$$
\frac{1}{c_{f}}=\rho \frac{\mathrm{d} p_{1}}{\mathrm{~d} \rho} .
$$

In (1), $c_{f}$ is the compression coefficient and $\rho$ is the density.

According to the formulas

$$
\begin{gathered}
\mathrm{d} \rho=\frac{-q \mathrm{~d} t}{B} \\
q=\rho A V,
\end{gathered}
$$

we can obtain

$$
\begin{aligned}
& \frac{\mathrm{d} p_{1}}{\mathrm{~d} t}=-\frac{A V}{c_{f} B}, \\
& \frac{\mathrm{d} p_{2}}{\mathrm{~d} t}=-\frac{A V}{c_{f} B} .
\end{aligned}
$$

From (4) and (5), we can get

$$
\begin{aligned}
\frac{\mathrm{d}\left(p_{2}-p_{1}\right)}{\mathrm{d} t} & =2 \frac{A V}{c_{f} B}, \\
V & =\frac{c_{f} B H}{2 A} \frac{\mathrm{d} \xi}{\mathrm{d} t},
\end{aligned}
$$

where $\xi$ is the hydraulic pressure gradient of rock sample, $\xi=\left(p_{1}-p_{2}\right) / H$. 


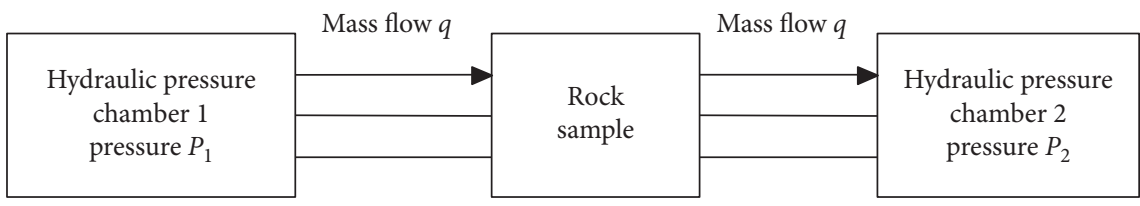

FIgURE 5: Principle of the transient permeation test system.

3.1. Calculation of Darcy Flow Permeability Parameters. For Darcy flow, the permeability velocity and pressure gradient follow the following formula:

$$
\xi=-\frac{u}{k_{D}} V,
$$

where $\varepsilon_{2}^{e}$ is the dynamic viscosity of the permeable liquid and $\varepsilon_{3}^{e}$ is the permeability of Darcy flow of the rock sample. Substituting (7) into (8),

$$
\frac{\mathrm{d} \xi}{\mathrm{d} t}=-2 \frac{A k_{D}}{c_{f} B H u} \xi
$$

In the experiment, sampling at equal interval $t$ in the test, the total number of samplings is $n$. The end of sampling is $\sigma_{f w}$. The hydraulic pressure gradient at the end of sampling is $\sigma_{f}$. Integrating (9), we can get

$$
\operatorname{In} \frac{\xi_{0}}{\xi_{f}}=2 \frac{A k_{D} t_{f}}{c_{f} B H u},
$$

where the hydraulic pressure gradients $\xi$ and $\xi_{0}$ are negative and $\xi_{0} / \xi$ is positive. Therefore, $\operatorname{In}\left(\xi_{0} / \xi\right)$ is meaningful. The permeability of rock sample can be calculated from (10). One has

$$
k_{D}=\frac{c_{f} B H u}{2 t_{f} A} \operatorname{In} \frac{\xi_{0}}{\xi_{1}}=\frac{c_{f} B H u}{2 t f A} \frac{p_{10}-p_{20}}{p_{1 f}-p_{2 f}} .
$$

Equation (11) is the calculation formula of rock sample permeability obtained by transient method which is using MTS815 at present.

3.2. Calculation of Non-Darcy Permeability Parameters. The experimental study shows that, in many cases, the seepage flow of rock sample is non-Darcy flow, and its seepage law satisfies the Forchimer relation; that is,

$$
\rho c_{a} \frac{\mathrm{d} V}{\mathrm{~d} t}=-\xi-\frac{u}{k} V+\rho \beta V^{2},
$$

where $c_{a}$ is acceleration coefficient, $u$ is dynamic viscosity, $k$ is permeability, and $\beta$ is non-Darcy flow factor.

From (7), we get

$$
\frac{\mathrm{d} V}{\mathrm{~d} t}=\frac{c_{f} B H}{2 A} \frac{\mathrm{d}^{2} \xi}{\mathrm{d} t^{2}} .
$$

It is assumed that the time series of fracture hydraulic pressure difference collected by equal time interval $t$ during the test is $\Delta p_{i}=\left(p_{2}-p_{1}\right)_{t=i \tau}(i=1,2,3, \ldots, n)$. In this way, the sequence of hydraulic pressure gradient $\xi_{i}=\Delta p_{i} / H$ $(i=1,2,3, \ldots, n)$ can be calculated. The formula of time series for calculating the seepage velocity $V$ and change rate $\eta=\mathrm{d} V / \mathrm{d} t$ can be obtained by the difference between (7) and (13):

$$
\begin{aligned}
V_{i} & =\frac{c_{f} B H}{2 A} \frac{\xi_{i+1}-\xi_{i-1}}{2 \tau}, \quad(i=1,2,3, \ldots, n-1) . \\
\eta_{i} & =\frac{c_{f} B H}{2 A} \frac{\xi_{i+2}-2 \xi_{i}+\xi_{i-2}}{2 \tau}, \quad(i=1,2,3, \ldots, n-2) .
\end{aligned}
$$

From (12),

$$
\rho \beta V_{i}^{2}-\frac{u}{k} V_{i}-\rho c_{a} \eta_{i}-\xi_{i}=0, \quad(i=1,2,3, \ldots, n-2) .
$$

Constructive functional is as follows:

$$
\Pi=\sum_{i=2}^{N-2}\left(\rho \beta V_{i}^{2}-\frac{u}{k} V_{i}-\rho c_{a} \eta_{i}-\xi_{i}\right)^{2} .
$$
follows:

The extremum conditions of the functional are as

$$
\begin{aligned}
\frac{\partial \Pi}{\partial(\rho \beta)} & =0 \\
\left(\sum_{i=2}^{N-2} V_{i}^{4}\right) \rho \beta-\left(\sum_{i=2}^{N-2} V_{i}^{3}\right) \frac{u}{k}-\left(\sum_{i=2}^{N-2} \eta_{i} V_{i}^{2}\right) \rho c_{a}-\left(\sum_{i=2}^{N-2} \xi_{i} V_{i}^{2}\right) & =0 \\
\frac{\partial \Pi}{\partial(u / k)} & =0 \\
\left(\sum_{i=2}^{N-2} V_{i}^{3}\right) \rho \beta-\left(\sum_{i=2}^{N-2} V_{i}^{2}\right) \frac{u}{k}-\left(\sum_{i=2}^{N-2} \eta_{i} V_{i}\right) \rho c_{a}-\left(\sum_{i=2}^{N-2} \xi_{i} V_{i}\right) & =0
\end{aligned}
$$




$$
\begin{array}{r}
\frac{\partial \Pi}{\partial\left(\rho c_{a}\right)}=0 \\
\left(\sum_{i=2}^{N-2} V_{i}^{2} \eta_{i}\right) \rho \beta-\left(\sum_{i=2}^{N-2} V_{i} \eta_{i}\right) \frac{u}{k}-\left(\sum_{i=2}^{N-2} \eta_{i}^{2}\right) \rho c_{a}-\left(\sum_{i=2}^{N-2} \xi_{i} \eta_{i}\right)=0
\end{array}
$$

By combining $(18) \sim(20)$, we can get $\rho \beta, u / k$, and $\rho c_{a}$. Sometimes, the single time series of permeability velocity $V$ and its change rate $\eta$ calculated by difference is not smooth enough. In this case, polynomial can be used to fit the curve of the hydraulic pressure gradient varying with time scatter diagram, (7) and (13) can be derived to obtain a single time series of permeability velocity $V$, and its change rate $\eta$ in (18) $\sim$ (20) becomes

$$
\begin{gathered}
\Pi=\int_{0}^{t_{f}}\left(\rho \beta V^{2}-\frac{u}{k} V-\rho c_{a} \eta_{i}-\xi\right)^{2} \mathrm{~d} t \\
\left(\int_{0}^{t_{f}} V^{4} \mathrm{~d} t\right) \rho \beta-\left(\int_{0}^{t_{f}} V^{3} \mathrm{~d} t\right) \frac{u}{k}-\left(\int_{0}^{t_{f}} V^{2} \eta \mathrm{d} t\right) \rho c_{a}=\int_{0}^{t_{f}} V^{2} \xi \mathrm{d} t \\
\left(\int_{0}^{t_{f}} V^{3} \mathrm{~d} t\right) \rho \beta-\left(\int_{0}^{t_{f}} V^{2} \mathrm{~d} t\right) \frac{u}{k}-\left(\int_{0}^{t_{f}} V \eta \mathrm{d} t\right) \rho c_{a}=\int_{0}^{t_{f}} V \xi \mathrm{d} t \\
\left(\int_{0}^{t_{f}} V^{2} \eta \mathrm{d} t\right) \rho \beta-\left(\int_{0}^{t_{f}} V \eta \mathrm{d} t\right) \frac{u}{k}-\left(\int_{0}^{t_{f}} \eta^{2} \mathrm{~d} t\right) \rho c_{a}=\int_{0}^{t_{f}} \eta \xi \mathrm{d} t .
\end{gathered}
$$

\section{Analysis of Test Results}

4.1. Non-Darcy Effect of Rock Fracture Seepage. The transient pulse penetration test was carried out on Maokou limestone. The percolation liquid was distilled water, its mass density is $1000 \mathrm{~kg} / \mathrm{m}^{3}$, its dynamic viscosity is $1.01 \times 10-3 \mathrm{~Pa} \cdot \mathrm{s}$, and its compression coefficient is $0.556 \times 10^{-9} \mathrm{~Pa}^{-1}$. The volume of two chambers in MTS hydraulic pressure system is $0.336 \times 10^{-6} \mathrm{~m}^{3}$.

Figure 6 shows the decay curve of hydraulic pressure difference of $\mathrm{M} 07$ with time under an axial pressure of $6 \mathrm{MPa}$ and different confining pressures. From Figure 6, we can find that the hydraulic pressure difference decreases rapidly in the early stage, slows down in the later stage, and finally approaches plateau. This is due to the decrease in the hydraulic pressure difference, which reduces the water seepage velocity. With the increase of confining pressure, the time required for the hydraulic pressure difference to reach equilibrium state increases significantly. This is due to the increase of confining pressure, which closes the rock fissures and creates greater resistance to water seepage. Using (11) to fit the test curve, the fitting curve is also shown in each figure.
From each figure, it is found that the curve drawn by exponential formula (11) derived from Darcy's law is quite different from the test data, and with the increase of confining pressure, the deviation between fitting curve and test data is greater.

The hydraulic pressure difference decay-time curve can be fitted by the quartic polynomial, and the fitting has a very high fitting precision. Table 3 is the quartic polynomial fitting equation of hydraulic pressure difference varying with time of M07 under different confining pressures.

This shows that the flow of fractured rock is a non-Darcy flow, which is time-varying. With the increase of confining pressure, the non-Darcy seepage effect of fractured rock is more obvious. The non-Darcy effect of fractured rock seepage is affected by confining pressure. When the confining pressure is low, the seepage of rock fracture is close to Darcy flow, and the seepage of rock fracture under high confining pressure is significant non-Darcy flow.

The volume pressure can be expressed as $\Theta=\sigma_{1}+2 \sigma_{3}$.

The fitting equation under axial pressure of $6 \mathrm{MPa}$ and confining pressure of $8 \mathrm{MPa}$ is

$$
\Delta P=7.81 \times 10^{-13} t^{4}-3.62 \times 10^{-9} t^{3}+6.15 \times 10^{-6} t^{2}-4.84 \times 10^{-3} t+1.92
$$



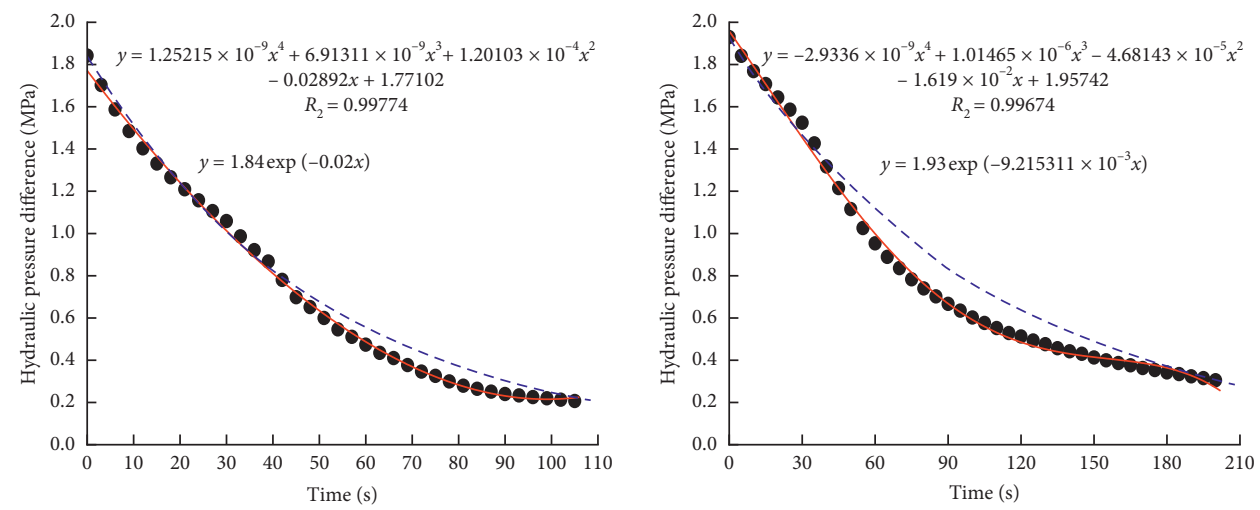

- Experimental data

Quartic polynomial fitting curve

_ - - Exponential fitting curve

(a)

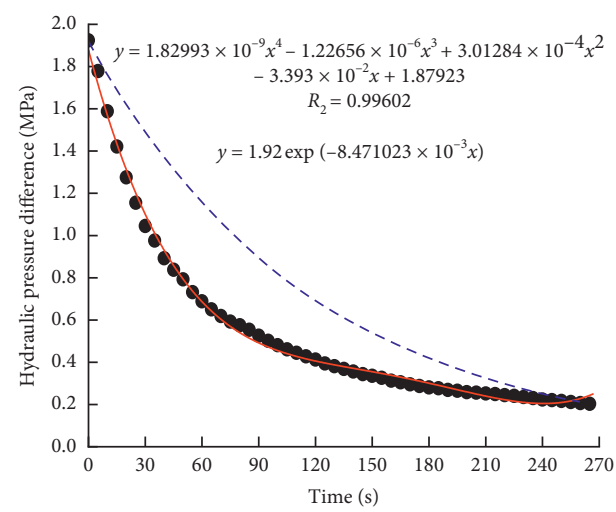

- Experimental data

_ Quartic polynomial fitting curve

- - - Exponential fitting curve

(b)

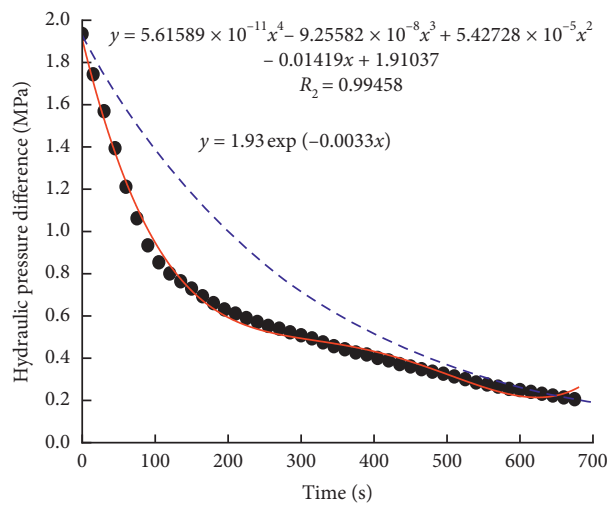

- Experimental data

Quartic polynomial fitting curve

- - - Exponential fitting curve

- Experimental data

__ Quartic polynomial fitting curve

_ - _ Exponential fitting curve

(c)

(d)
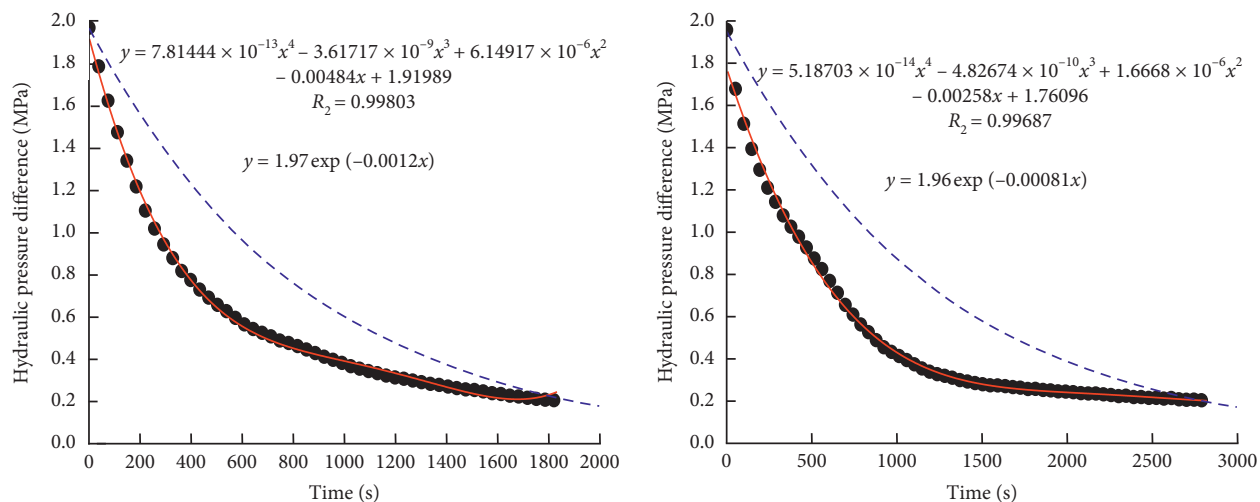

- Experimental data

Quartic polynomial fitting curve

- - - Exponential fitting curve

- Experimental data

Quartic polynomial fitting curve

- - - Exponential fitting curve

(e)

(f)

Figure 6: Hydraulic pressure decay-time data and the corresponding fitting curves for M07 specimen at a confining pressure of (a) 4 MPa; (b) $6 \mathrm{MPa}$; (c) $8 \mathrm{MPa}$; (d) $10 \mathrm{MPa}$; (e) $12 \mathrm{MPa}$; and (f) $14 \mathrm{MPa}$. 
TABLE 3: The quartic polynomial fitting equations of hydraulic pressure difference varying with time of M07 under different confining pressures.

\begin{tabular}{lcccc}
\hline $\begin{array}{l}\text { Axial pressure } \\
\sigma_{1} / \mathrm{MPa}\end{array}$ & $\begin{array}{c}\text { Confining } \\
\text { pressure } \\
\sigma_{3} / \mathrm{MPa}\end{array}$ & $\begin{array}{c}\text { Volume } \\
\text { pressure } \\
\Theta / \mathrm{MPa}\end{array}$ & $\begin{array}{c}\text { Quartic polynomial fitting curve of hydraulic pressure difference varying } \\
\text { with time }\end{array}$ & $\begin{array}{c}\text { Correlation } \\
\text { coefficient } \mathrm{R}^{2}\end{array}$ \\
\hline & 4 & 14 & $\Delta P=1.25 \times 10^{-9} t^{4}+6.91 \times 10^{-9} t^{3}+1.20 \times 10^{-5} t^{2}-2.89 \times 10^{-2} t+1.77$ & 0.998 \\
& 6 & 18 & $\Delta P=2.93 \times 10^{-9} t^{4}+1.01 \times 10^{-6} t^{3}-4.68 \times 10^{-5} t^{2}-1.61 \times 10^{-2} t+1.96$ & 0.997 \\
6 & 8 & 22 & $\Delta P=1.83 \times 10^{-9} t^{4}-1.23 \times 10^{-6} t^{3}+3.01 \times 10^{-4} t^{2}-3.39 \times 10^{-2} t+1.88$ & 0.996 \\
& 10 & 26 & $\Delta P=5.62 \times 10^{-11} t^{4}-9.26 \times 10^{-8} t^{3}+5.43 \times 10^{-5} t^{2}-1.42 \times 10^{-2} t+1.91$ & 0.995 \\
& 12 & 30 & $\Delta P=7.81 \times 10^{-13} t^{4}-3.62 \times 10^{-9} t^{3}+6.15 \times 10^{-6} t^{2}-4.84 \times 10^{-3} t+1.92$ & 0.998 \\
& 14 & 34 & $\Delta P=5.19 \times 10^{-14} t^{4}-4.83 \times 10^{-10} t^{3}+1.67 \times 10^{-6} t^{2}-2.58 \times 10^{-3} t+1.76$ & 0.997 \\
\hline
\end{tabular}

Hydraulic pressure gradient can be expressed as

$$
\xi=7.81 \times 10^{-12} t^{4}-3.62 \times 10^{-8} t^{3}+6.15 \times 10^{-5} t^{2}-4.84 \times 10^{-2} t+1.92
$$

The seepage velocity yields

$$
V=\frac{c_{f} B H}{2 A} \frac{\mathrm{d} \xi}{\mathrm{d} t}=4.76 \times 10^{-15}\left(3.124 \times 10^{-13} t^{3}-1.086 \times 10^{-9} t^{2}+1.23 \times 10^{-6} t-4.84 \times 10^{-2}\right) .
$$

According to the fitting equation, there is no linear relationship between the hydraulic pressure gradient and the seepage velocity, indicating that the seepage of Maokou limestone does not obey Darcy flow.

According to the data collected from the experiment, the permeability characteristic parameters of non-Darcy flow are calculated.

4.2. Seepage Characteristics under the Action of Hydromechanical Coupling. From Figure 7, it can be observed that the permeability of rock sample M07 decreases with the increase of volume stress. Under the action of low volume stress, the permeability change is more sensitive, and under the action of high volume stress, the permeability change is slow, because, at the initial stage of volume stress loading, the rock fracture has closed to a large extent, which has great resistance to the seepage of water and reduces the permeability. With the increase of volume stress, the rock fracture is further closed. When the fracture opening is close to the residual gap width, further increase of volume stress will maintain the residual gap width rather than close the rock fracture further, resulting in the fact that the permeability of fractured rock has little correlation with stress under the condition of high volume stress.

The $\beta$ factor of non-Darcy is a parameter to indicate the degree of seepage deviating from Darcy flow, which is related to seepage coefficient and porosity. When $\beta$ factor of non-Darcy is 0, the seepage flow is in Darcy flow state. When $\beta$ factor of non-Darcy is negative, the seepage is in a state of instability. From Figure 8 , it is shown that when the volume stress increases from $14 \mathrm{MPa}$ to $34 \mathrm{MPa}$, the $\beta$ factor of non-Darcy flow fluctuates greatly. When the volume stress is $14 \mathrm{MPa}$, the value of $\beta$ factor is very small, which means that the seepage is close to Darcy flow. When the volume stress is $26 \mathrm{MPa}$, the $\beta$ factor is at the maximum value, and the seepage deviates from Darcy flow to the maximum extent. When the volume stress is $30 \mathrm{MPa}$, the $\beta$ factor is in a negative value, indicating that the seepage is in a state of instability. When the volume stress is $34 \mathrm{MPa}$, the value of $\beta$ factor decreases to a lower value, and the degree of seepage deviation from Darcy flow is lower. It is noted that, in the early stage of the volume stress loading, the $\beta$ factor generally increases, which is due to the closure of the rock fracture under the volume stress, making the seepage deviate from the Darcy flow. In the later stage of volume stress loading, the fracture and pore passage in the rock have complex changes, and the degree of seepage deviating from Darcy flow is reduced.

Acceleration coefficient $c_{a}$ is an index reflecting the seepage inertia. The greater the acceleration coefficient is, the more difficult it is to change the flow state. The process of crack and fracture expansion and porosity increase is the process of inertia weakening, that is, the process of acceleration coefficient decreasing, as well as the process of transformation from steady flow to unsteady flow. From Figure 9, it can be observed that when the acceleration coefficient $c a$ is always increasing, the volume stress is loaded from $14 \mathrm{MPa}$ to $22 \mathrm{MPa}$. When the volume stress is from $26 \mathrm{MPa}$ to $34 \mathrm{MPa}$, the value of acceleration coefficient $c a$ is small, with small variation. It is noted that, under the action of low volume stress, rock fracture 


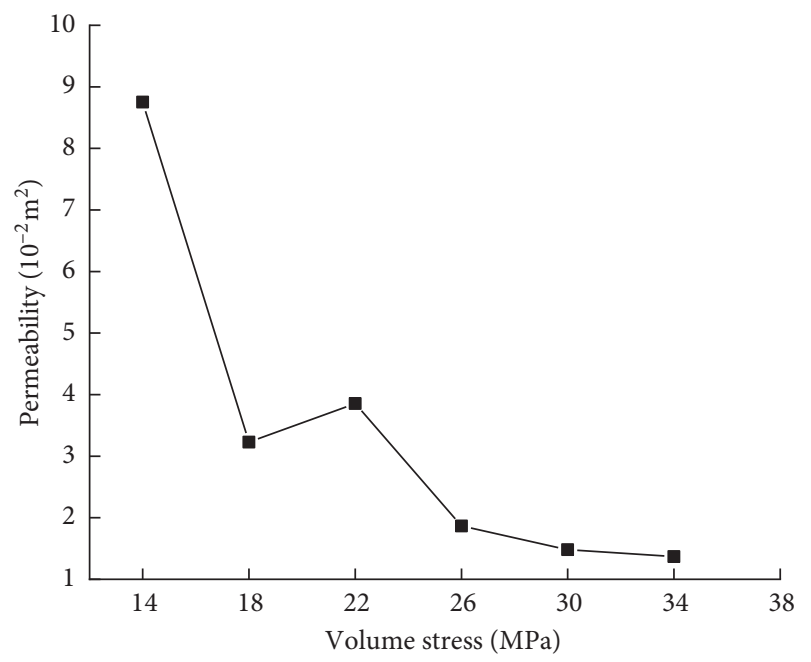

Figure 7: The curve of permeability versus volume stress.

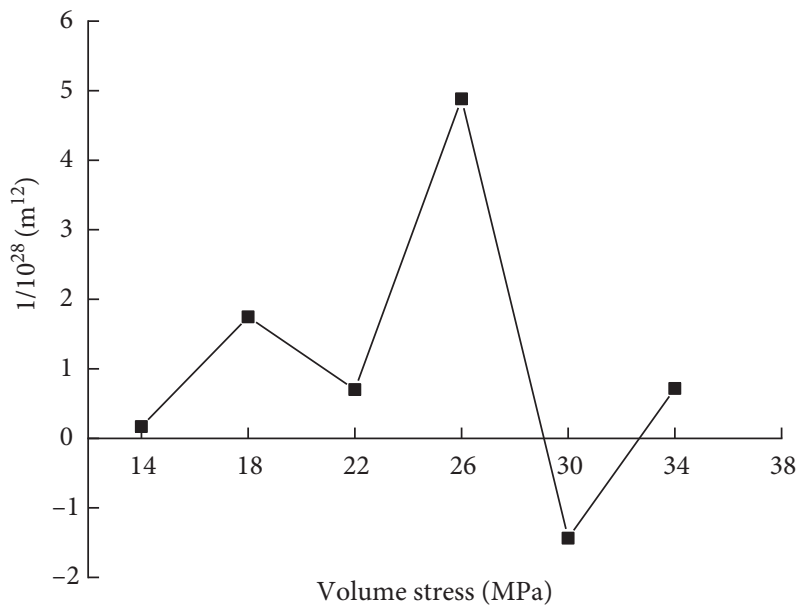

Figure 8: The curve of $\beta$ factor versus volume stress.

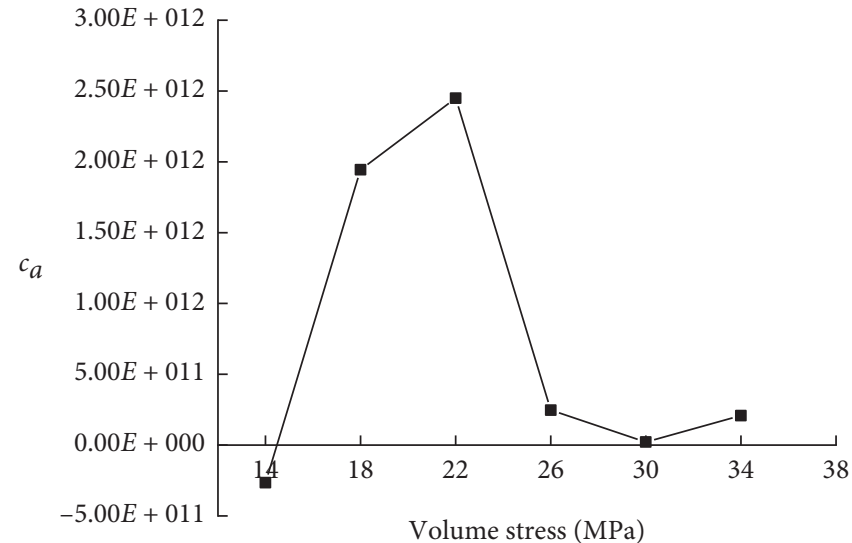

FIgURE 9: The curve of acceleration coefficient $c_{a}$ versus volume stress. 


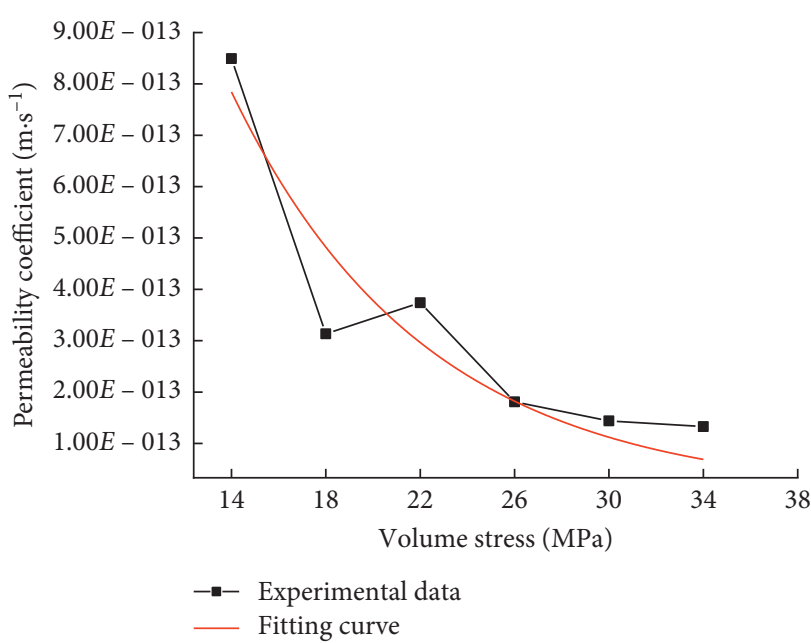

FIgURE 10: The curve of permeability coefficient versus volume stress.

is gradually compacted and acceleration coefficient $c a$ increases gradually, while under the action of high volume stress, complex changes have taken place in the internal fractures and pore channels of rocks and the acceleration coefficient $c a$ decrease.

4.3. Seepage Law under the Combined Action of Volume Stress and Hydraulic Pressure Difference. By analyzing the test data of non-Darcy flow obtained from the seepage test of fractured rock, the fitting relationship between the permeability coefficient of fractured rock, volume stress, and hydraulic pressure difference can be obtained based on the transient pulse method

$$
K=a \exp (-b \Theta+c \Delta p)
$$

where $a, b$, and $\mathrm{c}$ are the fitting parameters; $\Theta=\sigma_{1}+2 \sigma_{3}$ is volume stress, unit: MPa; $K$ is the permeability coefficient, unit: $\mathrm{m} / \mathrm{s}$; and $\Delta p$ is the hydraulic pressure difference, unit: $\mathrm{MPa}$.

Equation (28) is used to fit the test data, and the equation of fluid-solid coupling of fractured rock permeability coefficient $K=9.74 \times 10^{-13} \exp (-0.12 \Theta+0.74 \Delta p)$ is obtained. The fitting curve is shown in Figure 10.

From the analysis of the test data, we can draw the conclusions that, under the same axial pressure, the permeability coefficient of rock sample decreases continuously with the volume stress increases. Under the action of low volume stress, the permeability coefficient change is more sensitive, and under the action of high volume stress, the permeability coefficient change is slow. This is because, at the initial stage of confining pressure loading, the rock fracture has closed to a large extent, which has great resistance to the seepage of water and reduces the permeability coefficient. With the increase of confining pressure, the rock fracture is further closed. When the fracture opening is close to the residual gap width, further increase of confining pressure will maintain the residual gap width rather than close the rock fracture further, resulting in the fact that the permeability coefficient of rock fracture has little correlation with stress under high volume stress.

\section{Conclusions}

The transient seepage test of fractured Maokou limestone is carried out based on MTS815 rock mechanics test system. The non-Darcy seepage characteristics of fractured rock under confining pressure are extracted by a single time series of hydraulic pressure difference to analyze the relationship among seepage characteristics, stress. Through the experimental study, the main conclusions of this paper are as follows:

(1) Under the action of confining pressure, the hydraulic pressure difference of fractured rock is not in accordance with the specific exponential decay law. There is a significant difference between fractured rock seepage and Darcy flow. In the process of fractured rock transient pulse seepage test, the hydraulic pressure gradient and seepage velocity meet the Forchimer relationship rather than Darcy law. The equation of hydraulic pressure difference varying with time can be fitted by quartic polynomial.

(2) With the confining pressure increase, the non-Darcy seepage effect of rock fracture seepage is more obvious. And the seepage of rock fracture which under high confining pressure is a kind of highly nonlinear time-varying seepage.

(3) The permeability coefficient of fractured rock is affected by volume stress; the permeability coefficient decreases with the increase of volume stress. The relationship between permeability coefficient and stress is more sensitive while being under the action of low volume stress and it is not significant while being under the action of high volume stress.

(4) During the process of volume stress increasing, the $\beta$ factor of non-Darcy flow appears negative. Under the action of low volume stress, the acceleration coefficient and $\beta$ factor of non-Darcy flow increase, while under the action of high volume stress, the acceleration coefficient and $\beta$ factor of non-Darcy flow decrease.

\section{Data Availability}

The data used to support the findings of this study are included within the article.

\section{Conflicts of Interest}

The authors declare that they have no conflicts of interest.

\section{Acknowledgments}

This research was supported by the National Natural Science Foundation of China (nos. 51774131, 51274097, and 
51434006), the CRSRI Open Research Program (CKWV2017508/KY), and the Open Projects of State Key Laboratory of Coal Resources and Safe Mining, CUMT (no. SKLCRSM16KF12).

\section{References}

[1] D. Ma, X. X. Miao, Z. Q. Chen, and X. B. Mao, "Experimental investigation of seepage properties of fractured rocks under different confining pressures," Rock Mechanics and Rock Engineering, vol. 46, no. 5, pp. 1135-1144, 2013.

[2] T. Z. Li, Y. S. Li, and Z. G. Ma, "Testing study of non-darcian seepage flow in fractured rocks," Engineering Mechanics, vol. 20, no. 4, pp. 132-135, 2003.

[3] J. Jiang, D. Ehret, W. Xiang et al., "Numerical simulation of qiaotou landslide deformation caused by drawdown of the three gorges reservoir, China," Environmental Earth Sciences, vol. 62, no. 2, pp. 411-419, 2011.

[4] H. L. Kong and L. Z. Wang, "Seepage problems on fractured rock accompanying with mass loss during excavation in coal mines with karst collapse columns," Arabian Journal of Geosciences, vol. 11, no. 19, p. 585, 2018.

[5] Y. L. Zhao, L. Y. Zhang, W. J. Wang, Q. Liu, L. M. Tang, and G. M. Cheng, "Experimental study on shear behavior and a revised shear strength model for infilled rock joints," International Journal of Geomechanics, vol. 20, no. 9, Article ID 04020141, 2020.

[6] L. Algive, S. Békri, F. H. Nader, O. Lerat, and O. Vizika, "Impact of diagenetic alterations on the petrophysical and multiphase flow properties of carbonate rocks using a reactive pore network modeling approach," Oil \& Gas Science and Technology - Revue D'IFP Energies Nouvelles, vol. 67, no. 1, pp. 147-160, 2012.

[7] B. Dverstorp and J. Andersson, "Application of the discrete fracture network concept with field data: possibilities of model calibration and validation," Water Resources Research, vol. 25, no. 3, pp. 540-550, 1989.

[8] Y. L. Zhao, P. Cao, Y. X. Wang, and Y. K. Liu, "Coupling model of seepage-damage-fracture in fractured rock masses and its application," Chinese Journal of Rock Mechanics and Engineering, vol. 27, no. 8, pp. 1634-1643, 2008.

[9] S. Zhang, S. F. Cox, and M. S. Paterson, "The influence of room temperature deformation on porosity and permeability in calcite aggregates," Journal of Geophysical Research, vol. 99, no. B8, pp. 15761-15775, 1994.

[10] W. F. Brace, J. B. Walsh, and W. T. Frangos, "Permeability of granite under high pressure," Journal of Geophysical Research, vol. 73, no. 6, pp. 2225-2236, 1968.

[11] J.-A. Wang and H. D. Park, "Fluid permeability of sedimentary rocks in a complete stress-strain process," Engineering Geology, vol. 63, no. 3-4, pp. 291-300, 2002.

[12] J. Bi and X. P. Zhou, "A novel numerical algorithm for simulation of initiation, propagation and coalescence of flaws subject to internal fluid pressure and vertical stress in the framework of general particle dynamics," Rock Mechanics and Rock Engineering, vol. 50, no. 7, pp. 1833-1849, 2017.

[13] M. Wang and W. Wan, "A new empirical formula for evaluating uniaxial compressive strength using the Schmidt hammer test," International Journal of Rock Mechanics and Mining Sciences, vol. 123, Article ID 104094, 2019.

[14] X.-P. Zhou, Y.-T. Wang, and Y.-D. Shou, "Hydromechanical bond-based peridynamic model for pressurized and fluiddriven fracturing processes in fissured porous rocks,"
International Journal of Rock Mechanics and Mining Sciences, vol. 132, p. 104383, 2020.

[15] M. Wang, W. Wan, and Y. L. Zhao, "Experimental study on crack propagation and coalescence of rock-like materials with two pre-existing fissures under biaxial compression," Bulletin of Engineering Geology and the Environment, vol. 79, no. 6, pp. 3121-3144, 2020.

[16] X. X. Miao, S. C. Li, Z. Q. Chen, and W. Q. Liu, "Experimental study of seepage properties of broken sandstone under different porosities," Transport in Porous Media, vol. 86, no. 3, pp. 805-814, 2011.

[17] D. Ma, X. X. Miao, G. H. Jiang, H. B. Bai, and Z. Q. Chen, “An experimental investigation of permeability measurement of water flow in crushed rocks," Transport in Porous Media, vol. 105, no. 3, pp. 571-595, 2014.

[18] T. D. Rathnaweera, P. G. Ranjith, and M. S. A. Perera, "Effect of salinity on effective $\mathrm{CO} 2$ permeability in reservoir rock determined by pressure transient methods: an experimental study on hawkesbury sandstone," Rock Mechanics and Rock Engineering, vol. 48, no. 5, pp. 2093-2110, 2015.

[19] Y. K. Cheng, Z. Q. Chen, X. X. Miao, and X. B. Mao, "Testing study on permeability of non-Darcy flow in post-peak sandstone," Chinese Journal of Rock Mechanics and Engineering, vol. 23, no. 12, pp. 2005-2009, 2004.

[20] X. S. Wang and Z. Q. Chen, "Hydrodynamic analysis of transient method in rock seepage tests," Chinese Journal of Rock Mechanics and Engineering, vol. 25, no. 2, pp. 3098-3103, 2006.

[21] J. J. Liu, X. G. Liu, and Y. R. Hu, "Study on nonlinear seepage of rock of low permeability," Chinese Journal of Rock Mechanics and Engineering, vol. 22, no. 4, pp. 556-561, 2003.

[22] P. A. Hsieh, J. V. Tracy, C. E. Neuzil, J. D. Bredehoeft, and S. E. Silliman, "A transient laboratory method for determining the hydraulic properties of 'tight' rocks-I. Theory," International Journal of Rock Mechanics and Mining Sciences \& Geomechanics Abstracts, vol. 18, no. 3, pp. 245-252, 1981.

[23] V. I. Malkovsky, A. V. Zharikov, and V. M. Shmonov, "New methods for measuring the permeability of rock samples for a single-phase fluid," Izvestiya, Physics of the Solid Earth, vol. 45, no. 2, pp. 89-100, 2009.

[24] H. Jang, J. Lee, and W. Lee, "Experimental apparatus and method to investigate permeability and porosity of shale matrix from haenam basin in Korea," Environmental Earth Sciences, vol. 74, no. 4, pp. 3333-3343, 2015.

[25] M. Mokhtari and A. N. Tutuncu, "Characterization of anisotropy in the permeability of organic-rich shales," Journal of Petroleum Science and Engineering, vol. 133, pp. 496-506, 2015.

[26] F. Fedor, G. Hamos, A. Jobbik, Z. Mathe, G. Somodi, and I. Szücs, "Laboratory pressure pulse decay permeability measurement of boda claystone, mecsek mts., sw hungary," Physics and Chemistry of The Earth, vol. 33, pp. 45-53, 2008.

[27] S. Ghabezloo, J. Sulem, and J. Saint-Marc, "Evaluation of a permeability-porosity relationship in a low-permeability creeping material using a single transient test," International Journal of Rock Mechanics and Mining Sciences, vol. 46, no. 4, pp. 761-768, 2009.

[28] P. G. Ranjith and D. R. Viete, "Applicability of the 'cubic law' for non-darcian fracture flow," Journal of Petroleum Science and Engineering, vol. 78, no. 2, pp. 321-327, 2011.

[29] Y. L. Zhao, L. Y. Zhang, J. Liao, W. J. Wang, Q. Liu, and L. M. Tang, "Experimental study of fracture toughness and subcritical crack growth of three rocks under different 
environments," International Journal of Geomechanics, vol. 20, no. 8, Article ID 04020128, 2020.

[30] A. P. Oron and B. Berkowitz, "Flow in fractures: the local cubic law assumption reexamined," Water Resources Research, vol. 34, no. 34, pp. 2811-2825, 1998.

[31] J. Qian, Z. Chen, H. Zhan, and H. Guan, "Experimental study of the effect of roughness and Reynolds number on fluid flow in rough-walled single fractures: a check of local cubic law," Hydrological Processes, vol. 25, no. 4, pp. 614-622, 2011.

[32] Y. Zhao, Y. Wang, W. Wang, L. Tang, Q. Liu, and G. Cheng, "Modeling of rheological fracture behavior of rock cracks subjected to hydraulic pressure and far field stresses," Theoretical and Applied Fracture Mechanics, vol. 101, pp. 59-66, 2019.

[33] S. C. Li, X. X. Miao, Z. Q. Chen, and X. B. Mao, "Experimental study on seepage properties of non-darcy flow in confined broken rocks," Engineering Mechanics, vol. 25, no. 4, pp. 85-92, 2008.

[34] Y. L. Zhao, L. Y. Zhang, W. J. Wang, J. Z. Tang, H. Lin, and W. Wan, "Transient pulse test and morphological analysis of single rock fractures," International Journal of Rock Mechanics and Mining Sciences, vol. 91, pp. 139-154, 2017.

[35] V. H. Nguyen, N. Gland, J. Dautriat, C. David, J. Wassermann, and J. Guélard, "Compaction, permeability evolution and stress path effects in unconsolidated sand and weakly consolidated sandstone," International Journal of Rock Mechanics and Mining Sciences, vol. 67, pp. 226-239, 2014.

[36] Y. Zhao, L. Zhang, W. Wang, C. Pu, W. Wan, and J. Tang, "Cracking and stress-strain behavior of rock-like material containing two flaws under uniaxial compression," Rock Mechanics and Rock Engineering, vol. 49, no. 7, pp. 26652687, 2016.

[37] Q. H. Wu, L. Weng, Y. L. Zhao, B. H. Guo, and T. Luo, "On the tensile mechanical characteristics of fine-grained granite after heating/cooling treatments with different cooling rates," Engineering Geology, vol. 253, pp. 94-110, 2019.

[38] X. P. Zhou and H. Q. Yang, "Multiscale numerical modeling of propagation and coalescence of multiple cracks in rock masses," International Journal of Rock Mechanics and Mining Sciences, vol. 55, pp. 15-27, 2012.

[39] Q. H. Wu, X. B. Li, L. Weng et al., "Experimental investigation of the dynamic response of prestressed rockbolt by using an shpb-based rockbolt test system," Tunnelling and Underground Space Technology, vol. 93, Article ID 103088, 2019.

[40] X.-P. Zhou, Y.-X. Zhang, Q.-L. Ha, and K.-S. Zhu, "Micromechanical modelling of the complete stress-strain relationship for crack weakened rock subjected to compressive loading," Rock Mechanics and Rock Engineering, vol. 41, no. 5, pp. 747-769, 2008.

[41] Q. Wu, L. Chen, B. Shen, B. Dlamini, S. Li, and Y. Zhu, "Experimental investigation on rockbolt performance under the tension load," Rock Mechanics and Rock Engineering, vol. 52, no. 11, pp. 4605-4618, 2019.

[42] Y. L. Zhao, L. Y. Zhang, W. J. Wang, W. Wan, and W. H. Ma, "Separation of elastoviscoplastic strains of rock and a nonlinear creep model," International Journal of Geomechanics, vol. 18, no. 1, Article ID 04017129, 2018.

[43] K. K. Singh, D. N. Singh, and P. G. Ranjith, "Laboratory simulation of flow through single fractured granite," Rock Mechanics and Rock Engineering, vol. 48, no. 3, pp. 987-1000, 2015.

[44] Y. Chen, P. Cao, R. Chen, and Y. Teng, "Effect of water-rock interaction on the morphology of a rock surface,"
International Journal of Rock Mechanics and Mining Sciences, vol. 47, no. 5, pp. 816-822, 2010.

[45] X. P. Zhou, G. Q. Li, and H. C. Ma, "Real-time experiment investigations on the coupled thermomechanical and cracking behaviors in granite containing three pre-existing fissures," Engineering Fracture Mechanics, vol. 224, Article ID 106797, 2020.

[46] O. Schulze, T. Popp, and H. Kern, "Development of damage and permeability in deforming rock salt," Engineering Geology, vol. 61, no. 2-3, pp. 163-180, 2001.

[47] X. P. Zhou, "Localization of deformation and stress-strain relation for mesoscopic heterogeneous brittle rock materials under unloading," Theoretical and Applied Fracture Mechanics, vol. 44, no. 1, pp. 27-43, 2005.

[48] M. Oda, T. Takemura, and T. Aoki, "Damage growth and permeability change in triaxial compression tests of inada granite," Mechanics of Materials, vol. 34, no. 6, pp. 313-331, 2002.

[49] B. Yuan, M. Sun, L. Xiong, Q. Luo, S. P. Pradhan, and H. Li, "Investigation of 3D deformation of transparent soil around a laterally loaded pile based on a hydraulic gradient model test," Journal of Building Engineering, vol. 28, Article ID 101024, 2020.

[50] B. X. Yuan, L. Xiong, L. H. Zhai et al., "Transparent synthetic soil and its application in modeling of soil-structure interaction using optical system," Frontiers in Earth Science, vol. 7, p. 276, 2019.

[51] M. G. Sun, X. W. Huang, T. Z. Li, G. Y. Lei, and X. B. Mao, "Seepage properties of non-darcy flow in complete failure process of limestone," Chinese Journal of Rock Mechanics and Engineering, vol. 25, no. 3, pp. 484-491, 2006. 